\title{
Determination of Azithromycin in Pharmaceutical Formulations by Differential Pulse Voltammetry. Comparison with Fourier Transformed Infrared Spectroscopic Analysis
}

\author{
J. Araujo, R. Ortíz, W. Velásquez, J.M. Ortega \\ Universidad de Los Andes, Facultad de Ciencias, Departamento de Química, \\ Laboratorio de Electroquímica, Mérida 5101, Venezuela
}

Received 7 March 2005; accepted in revised form 28 September 2005

\begin{abstract}
Differential Pulse Voltammetry (DPV) and Fourier Transformed Infrared Spectroscopy (FTIRS) techniques have been applied and compared, for the azithromycin determination in two different pharmaceutical formulations (capsules and suspension). Both methods were found to be highly precise with high recovery levels (more than 98 \%) The analytical results obtained with the electrochemical method showed excellent correlation with the analytical results obtained by FTIRS. The proposed electrochemical methodology presents the advantage over FTIRS of being able to be used directly on azithromycin samples in capsules presentation as well as in suspension, since no interferences were observed from the excipients of the formulation, nevertheless the direct analysis of the suspension was not possible by FTIRS due to excipients interference.
\end{abstract}

Keywords: azithromycin, antibiotic analysis, DPV analysis, electrochemical determination, FTIRS analysis.

\section{Introduction}

The azithromycin (Fig. 1) is the first member of a class of macrolide antibiotics which are called azalides [1]. This is a very efficient therapeutic agent for the oral treatment of sexually transmitted diseases, typical and atypical pneumonia, infections of the inferior and superior breathing tract and structural infections of the skin [2].

The analyses using high performance liquid chromatography with electrochemical detection has been described for azithromycin and other

\footnotetext{
* Corresponding author. E-mail address: reynaldo@ula.ve
} 
macrolides antibiotic [3-19] in a diversity of human fluids (blood, serum, urine). More recently, Othaman and collaborators [20] developed a voltammetric method for determination of azithromycin in clinical compounds and biological samples, using square wave voltammetry on carbon paste electrode as working electrode. Recently, adsorptive stripping voltammetric method on a glassy carbon electrode in aqueous media has been described for azithromycin determination in pharmaceutical formulations and urine, showing excellent results [20].

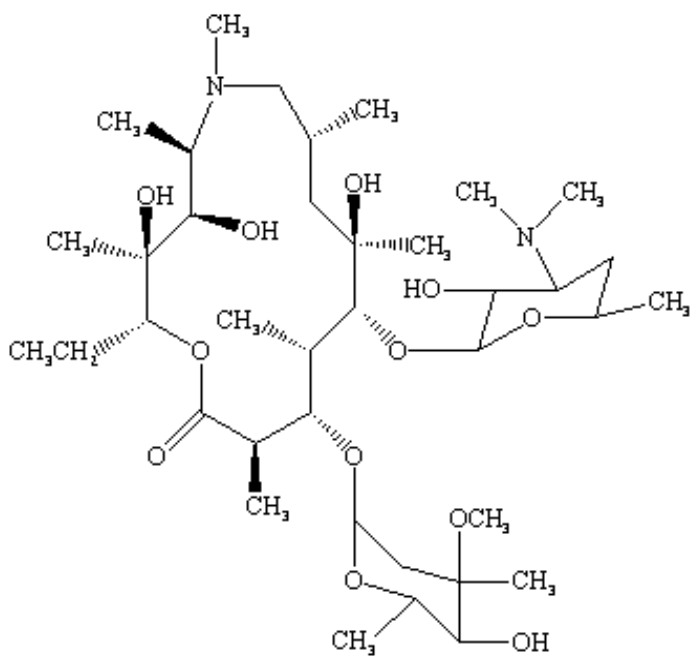

Figure 1. Structure of azithromycin.

Due to the high electroactivity of the azithromycin molecule and the low electroactivity of other compounds from the pharmaceutical preparations, it is possible to propose a direct electrochemical method for the quantitative determination of this antibiotic, without pre-treatment of the sample (other than dissolution, of course), which would be advantageous for routine procedures of quality control, for example. In this paper we propose the application of the voltammetric method to the assay of azithromycin in its pharmaceutical dosage, using organic media as solvent, i.e., acetonitrile, in which the azithromycin is much more soluble than in water.

Another popular technique for quantitative analysis is the FTIR spectroscopy, witch has been used for many years to identify or confirm the presence of many drugs and other chemicals. Infrared spectroscopic techniques enable the analysis of raw materials without time-consuming sample preparation methods and have been shown to be a promising tool for the analysis of a variety of samples, both direct procedure or as a method for chromatographic detection [20-22].

The aim of this work is the development of a fast and friendly electrochemical procedure for the determination of azithromycin in commercial pharmaceutical formulations, which could be applied for quality control purposes. Owing to the simplicity of the DPV analysis, it could be used with educational aims. A comparison between the differential pulse voltammetry (DPV) and FTIRS techniques, is reported in order to show that the results are reliable. 


\section{Experimental \\ Reagents}

The used reagents were of analytical grade without previous purification. The antibiotic solutions were prepared using ultrapure azithromycin (kindly provided by VALMORCA laboratories, Venezuela); for electrochemical experiments, supporting electrolyte was $0.3 \mathrm{M}$ tetrabutylammonium hexafluorophosphate $\left(\mathrm{Bu}_{4} \mathrm{NFP}_{6}\right)$ solution, in acetonitrile. For the spectroscopic method it was employed toluene as solvent. The series of solutions in growing concentrations of azithromycin were prepared by dilution, starting from a concentrated solution $(0.01 \mathrm{M})$ of the antibiotic. The analyzed real samples consisted on Venezuelan commercial medicaments that contain azithromycin as active species. All the experiments were carried out at constant temperature and after bubbling argon during two minutes to maintain the inert atmosphere during the whole process.

\section{Apparatus}

A single compartment $(10.0 \mathrm{~mL})$ and a three electrodes cell were used for the voltammetric experiments. A platinum spring-like wire $\left(0.8 \mathrm{~cm}^{2}\right.$ geometrical area) was used as working electrode; platinum foil $\left(1 \mathrm{~cm}^{2}\right.$ geometrical area) was used as counter electrode. Before each experiment the working electrode was immersed in concentrated $\mathrm{H}_{2} \mathrm{SO}_{4}$ and flamed to red; cyclic voltammogram of platinum in $0.5 \mathrm{M} \mathrm{H}_{2} \mathrm{SO}_{4}$ was used to monitor the cleanliness of the cell and the electrodes.

All the measures were carried out using, as reference electrode, a silver wire immersed in a $0.01 \mathrm{M} \mathrm{AgNO}_{3}$ in acetonitrile solution. A potentiostat/galvanostat EG\&G Princeton applied research model 263 coupled to a PC by means of a IEE-488 interface was used for the analysis and recording of data.

For the FTIR experiments, an adjustable transmission cell for liquids was used. This cell had $2 \mathrm{~mm}$ thick silicon windows and a $0.1 \mathrm{~mm}$ Teflon expatiator. A system 2000 FTIR spectrometer (Perkin-Elmer), with a liquid- $\mathrm{N}_{2}$-cooled mercury cadmium telluride (MCT) detector was employed.

\section{Measurement procedure}

Cyclic voltammograms from both, the blank and $1.0 \times 10^{-3} \mathrm{M}$ azithromycin solution were recorded with the purpose of selecting the optimal working conditions. The determined optimal conditions were: equilibrium time: $15 \mathrm{~s}$; scan rate: $100 \mathrm{mV} / \mathrm{s}$; potential range: from -0.500 to $+1.400 \mathrm{~V}$.

\section{Curve of calibration for Differential Pulse Voltammetry (DPV) experiments}

A series of solutions of growing concentration of azithromycin was prepared in the concentration range $(2-20) \times 10^{-5} \mathrm{M}$ in a $0.3 \mathrm{M} \mathrm{Bu}_{4} \mathrm{NFP}_{6} / \mathrm{CH}_{3} \mathrm{CN}$ solution, from which calibration plots (simple and standard addition) were built. The voltammograms for the electrolytic media in absence and in presence of the electroactive species were previously registered. The azithromycin solutions were analyzed by DPV in a potential range from 200 to $900 \mathrm{mV}$ vs. $\mathrm{Ag} / \mathrm{AgNO}_{3}$, on platinum to a scan rate of $5 \mathrm{mV} / \mathrm{s}$. The optimal conditions for analysis were: 
equilibrium time: $15 \mathrm{~s}$; pulse amplitude: $50 \mathrm{mV}$; wide of pulse: $50 \mathrm{~ms}$; current interval: $10 \mu \mathrm{A}$; filter: I $5.3 \mathrm{~Hz}$.

\section{Curve of calibration for FTIR experiments}

The FTIR spectra of dissolved azithromycin in toluene was taken in order to determine the wavenumber of the stretching vibration of the carbonyl group $(\mathrm{C}=\mathrm{O})$; this band was selected to carry out the quantitative analysis. A series of solutions of growing concentration of the drug was prepared in the $(4-16) \times 10^{-3}$ $M$ concentration interval, in toluene. These solutions got ready for dilution, starting from a concentrated solution of azithromycin 0.01 M. Spectra were taken in a 1650 to $1800 \mathrm{~cm}^{-1}$ wavenumber range and each spectrum was the average of 50 interferograms. Calibration plots (simple and standard addition) were built.

\section{Sample preparation}

\section{Capsule presentation}

The samples were obtained weighing the necessary quantity to prepare a 10.0 $\mathrm{mL}$ of $0.01 \mathrm{M}$ azithromycin solution. Then it was evened with a $0.30 \mathrm{M}$ of $\mathrm{Bu}_{4} \mathrm{NFP}_{6}$ in $\mathrm{CH}_{3} \mathrm{CN}$ solution. Next, an aliquot of $60.0 \mu \mathrm{L}$ of sample was injected in the electrochemical cell. The volume of the electrolyte was eventually adjusted to $5.0 \mathrm{~mL}$. The solutions containing the antibiotic were studied by voltammetry and FTIR spectroscopy. Azithromycin content was determined for triplicate with a number of samples equal to three.

\section{Suspension}

The samples were prepared by mixing the powder with the diluter. The mix was agitated enough to form a suspension. Next, $1.0 \mathrm{~mL}$ of the previous solution was transferred to a $10.0 \mathrm{~mL}$ volumetric flask; finally, the sample is evened with $\mathrm{Bu}_{4} \mathrm{NFP}_{6} / \mathrm{CH}_{3} \mathrm{CN}$ solution. Later on, an aliquot of $100 \mu \mathrm{L}$ of the sample was injected in the electrochemical cell; volume of the electrolyte was eventually adjusted to $5.0 \mathrm{~mL}$. Since the contained compounds in suspension interfere spectrally with azithromycin infrared features, this sample was studied only by voltammetry. The drug was determined by simple calibration method. Each determination was carried out for triplicate with a number of samples equal to three.

\section{Results and discussion}

\section{Cyclic voltammetry for the azithromycin oxidation}

Fig. 2 shows the cyclic voltammogram of the platinum in a $1.0 \times 10^{-3} \mathrm{M}$ azithromycin / $0.1 \mathrm{M} \mathrm{Bu}_{4} \mathrm{NFP}_{6} / \mathrm{CH}_{3} \mathrm{CN}$ solution. The voltammetric response of the antibiotic oxidation suggests an irreversible reaction. An oxidation peak is observed at $760 \mathrm{mV}$. According to Duthu [15], this peak can be attributed to the oxidation of both tertiary amine groups of the drug (in the positions 3 and $9 \mathrm{a}$ ). 
This inference is supported by the fact that the peak current of the azithromycin, under the same experimental conditions, is twice higher than the peak current from the erythromycin, since the latter possesses a single tertiary amine group; in a previous report we have confirmed this inference by spectroelectrochemical studies [16]. From cyclic voltammetry results, the selected working potential range went from 200 to $900 \mathrm{mV}$ vs. $\mathrm{Ag} / \mathrm{AgNO}_{3}$, since in this range potential a well defined oxidation peak is observed.

\section{Quantitative determination of azithromycin}

Differential pulse voltammetry (DPV)

In Fig. 3 we show a series of typical DPV voltammograms for the oxidation of the antibiotic on platinum at $5 \mathrm{mV} \mathrm{s}^{-1}$. A proportional response of the current intensity was observed for the oxidation peak as the concentration is increased. Adequate precision in the voltammetric signal was obtained by cleaning the electrode surface as described above before each measurement.

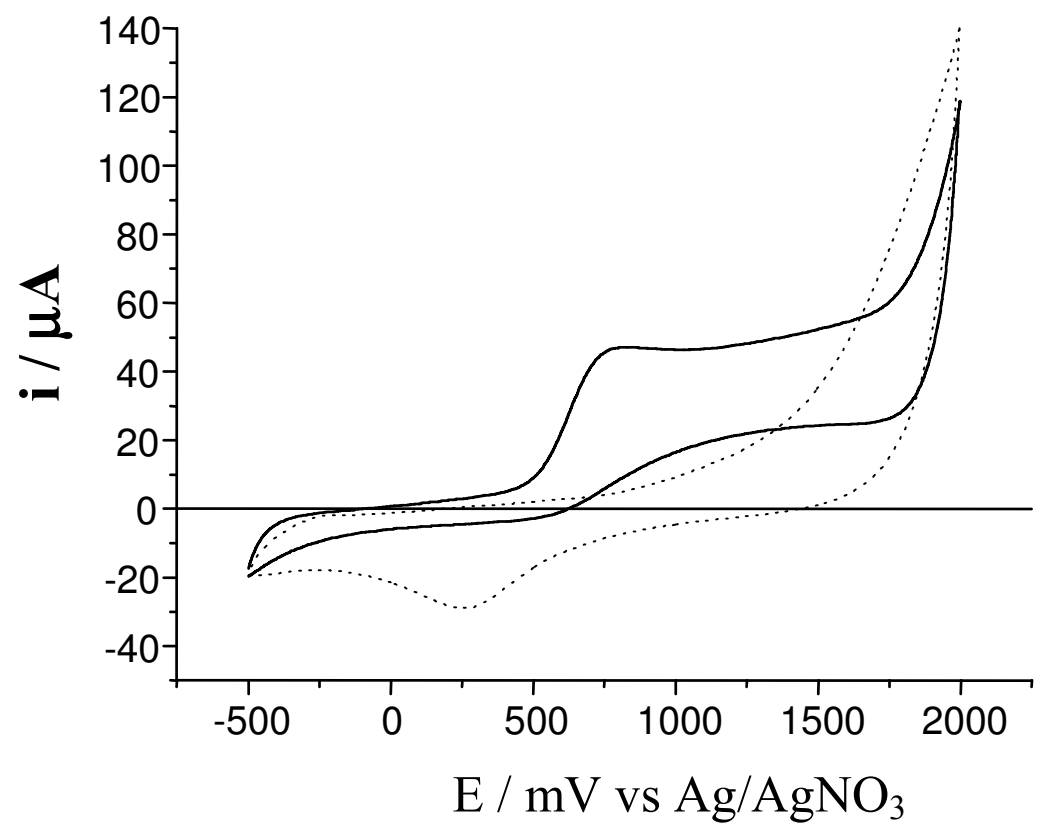

Figure 2. Cyclic voltammogram of platinum electrode immersed in a $1.0 \times 10^{-3} \mathrm{M}$ azithromycin / $\mathrm{Bu}_{4} \mathrm{NFP}_{6} / \mathrm{CH}_{3} \mathrm{CN}$ solution at a scan rate of $100 \mathrm{mV} \mathrm{s}^{-1}$. (Doted line corresponds to the blank response).

Plotting the peak current intensity as a function of the drug concentration, a lineal response is obtained. Fig. 4 and 5 show calibration curves obtained for capsule samples; the concentration of the analyte was determined from the slope (m) of the straight line for the simple calibration and from extrapolation of the standard concentration at $\mathrm{Ip}=0$. The same procedure was followed for the suspension presentation of the drug. The results for the analyses of $500 \mathrm{mg}$ capsules and $250 \mathrm{mg} / 5 \mathrm{~mL}$ suspension are summarized in Table I. 


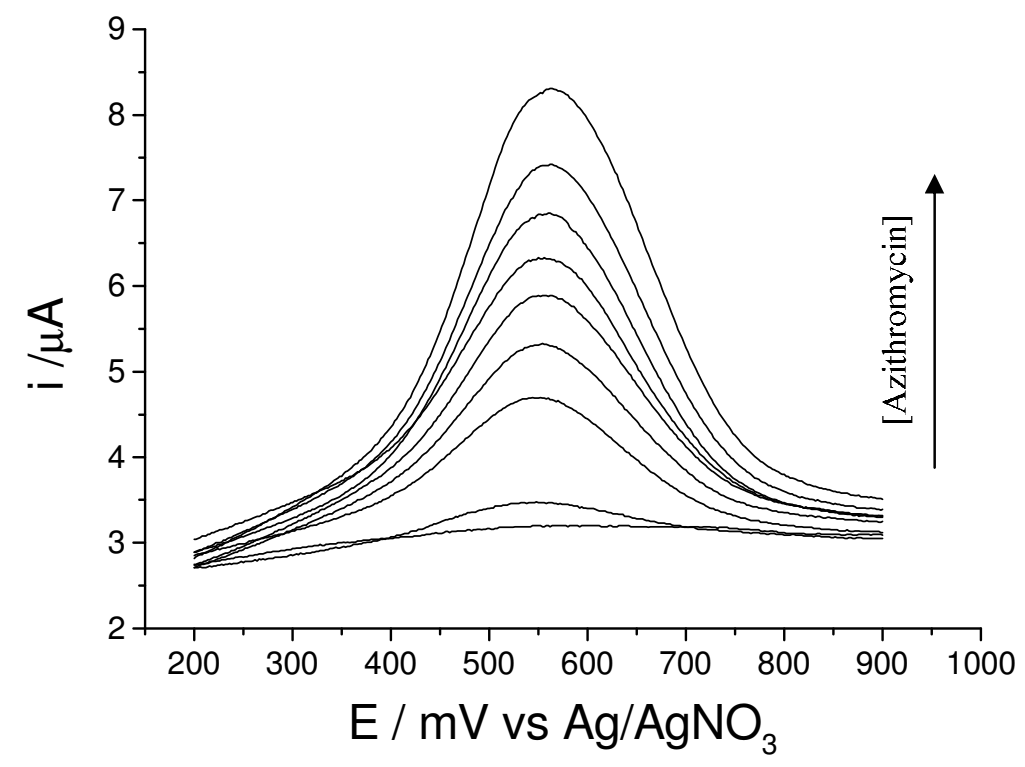

Figure 3. Differential pulse voltammograms for the oxidation of increasing concentrations of azithromycin on platinum at a scan rate of $5 \mathrm{mV} \mathrm{s}^{-1}$.

Table 1. Summary of the obtained results for two different azithromycin formulation samples.

\begin{tabular}{|c|c|c|c|c|c|}
\hline Matrix & $\begin{array}{c}\text { Technique/ } \\
\text { Calibration } \\
\text { mode }\end{array}$ & $\begin{array}{l}\text { Correlation } \\
\text { coefficient }\end{array}$ & $\begin{array}{c}\text { Recovery } \\
\%\end{array}$ & $\begin{array}{c}\text { Coefficient of } \\
\text { variation } \\
\%\end{array}$ & $\begin{array}{c}\text { Detection imit } \\
(\mathrm{mol} / \mathrm{L}) \\
(3 \mathrm{~s} \text { criterion })\end{array}$ \\
\hline Capsule & \multirow{2}{*}{$\begin{array}{l}\text { DPV/ simple } \\
\text { calibration }\end{array}$} & 0.99865 & 99.2 & 3.7 & $3.2 \times 10^{-6}$ \\
\hline Suspension & & 0.99907 & 101.2 & 1.0 & \\
\hline Capsule & \multirow[b]{2}{*}{$\begin{array}{c}\text { DPV/ addition } \\
\text { of standard }\end{array}$} & 0.99939 & 103.7 & 2.0 & \\
\hline Suspension & & 0.99981 & 105.7 & 1.3 & \\
\hline Capsule & $\begin{array}{c}\text { FTIRS/ simple } \\
\text { calibration }\end{array}$ & 0.99957 & 98.5 & 0.9 & $2.1 \times 10^{-4}$ \\
\hline Capsule & $\begin{array}{c}\text { FTIRS/ } \\
\text { addition of } \\
\text { standard }\end{array}$ & 0.99998 & 105.9 & 0.2 & \\
\hline
\end{tabular}

The analysis does not require an extraction method because the substances which are present in the pharmaceutical product do not interfere with the azithromycin response.

The F test, with a level of probability of $95 \%$, was applied to determine the significance of a difference between the values of normal deviation, which are related to the two series in discussion (simple and addition of standard calibration methods). Results suggest that there is not matrix effect; as a consequence of this, the analysis of azithromycin can be carried out using simple calibration. 


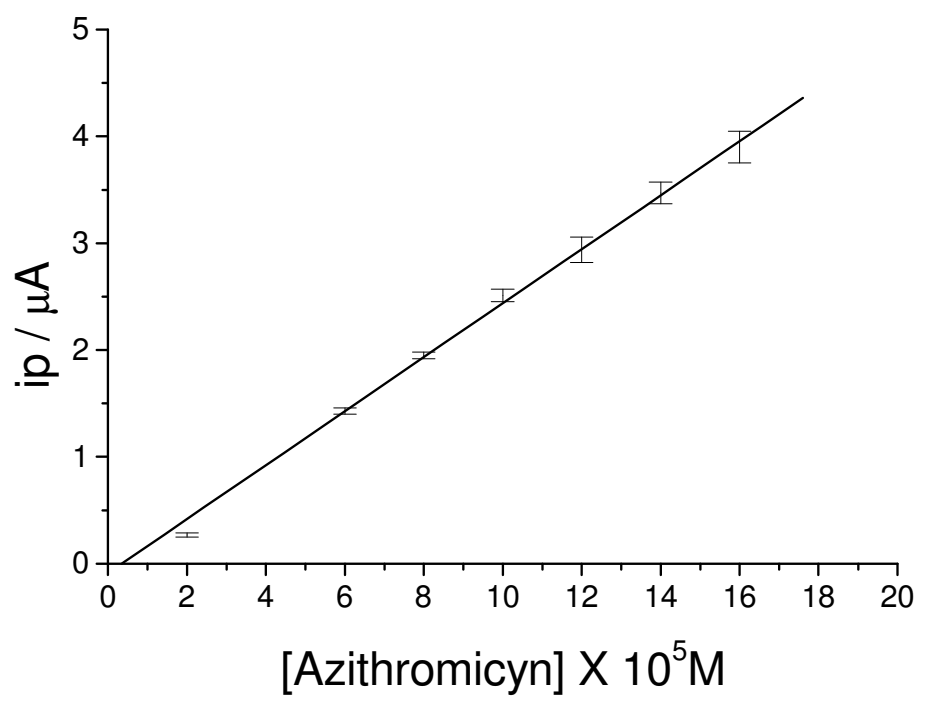

Figure 4. Simple calibration plot for azithromycin from DPV experiments. Analyte concentration was determined from the slope value.

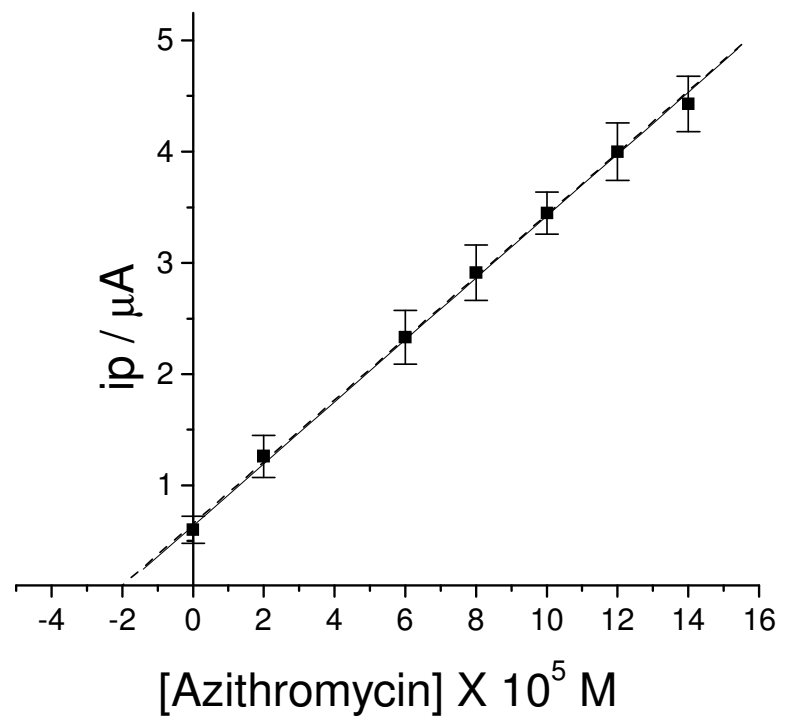

Figure 5. Addition of standard calibration plot for azithromycin (capsule presentation) from DPV experiments. Azithromycin concentration was calculated from extrapolation to concentration of azithromycin at $i_{p}=0$.

Fourier transformed infrared absorption spectroscopy (FTIRS)

Fig. 6 shows the FTIR spectrum of dissolved azithromycin in toluene. In the range of 4000 to $500 \mathrm{~cm}^{-1}$ azithromycin exhibits a strong sharp signal at 1728 $\mathrm{cm}^{-1}$, which is due to the absorption of the carbonyl group; this feature was taken for the quantitative analysis. 


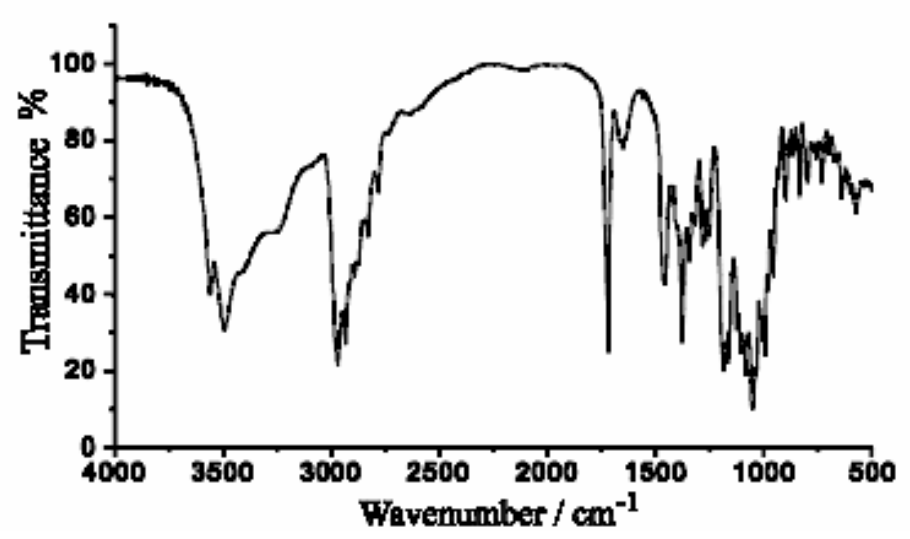

Figure 6. FTIR spectrum of dissolved azithromycin in toluene.

Fig. 7 illustrates a series of IR spectra in a close-up region where the absorption band of the carbonyl group is observed, for a drug concentration ranging from 4 to $16 \mathrm{mM}$. These figures show a proportional behavior of the absorbance as the antibiotic concentration increases. The carbonyl absorption band presents its maximum intensity at $1728 \mathrm{~cm}^{-1}$; no interfering overlapping was observed in that region.

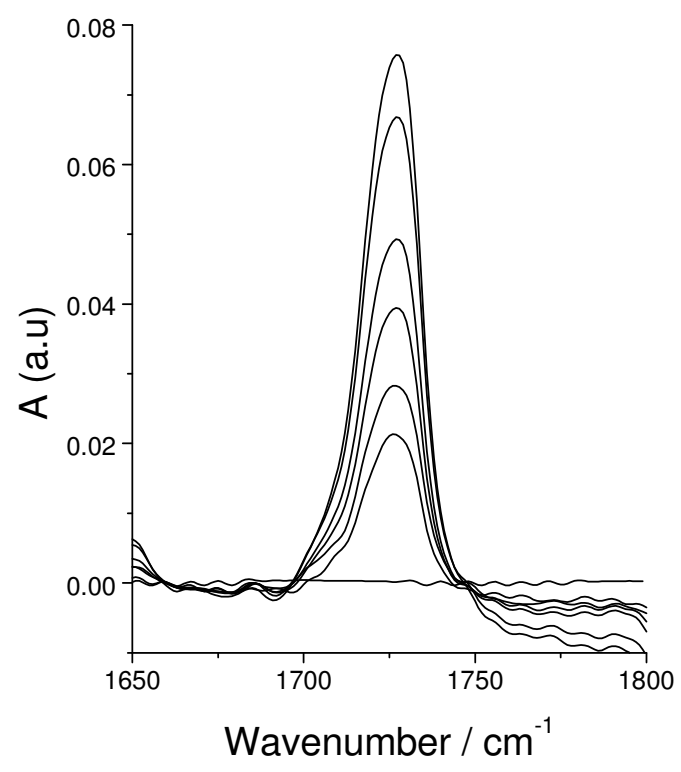

Figure 7. FTIR spectra of azithromycin solutions in toluene, in a close-up region of the carbonyl group absorption. Drug concentration range: 4 to $16 \mathrm{mM}$.

By using the Beer Lambert law, the calibration curves were built (Fig. 8 and 9). This result indicates that in the studied concentration range, azithromycin fulfills this law. 


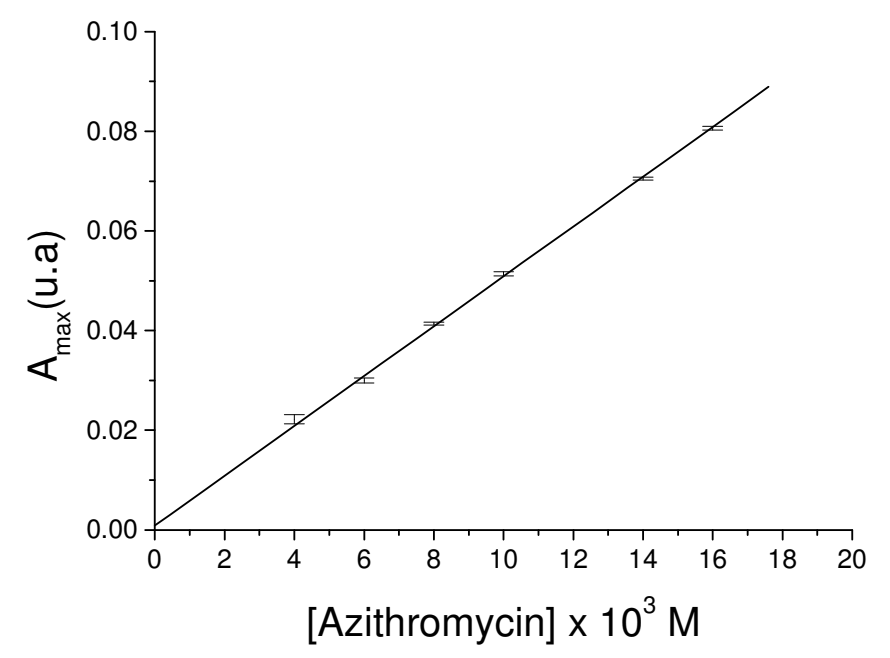

Figure 8. Simple calibration plot for azithromycin from FTIRS experiments.

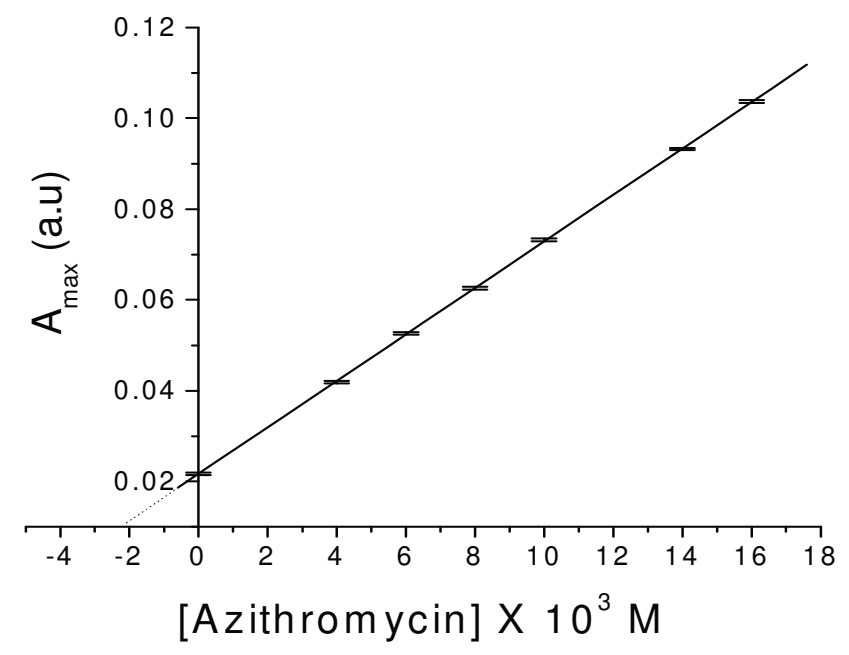

Figure 9. Addition of standard calibration plot for azithromycin in its capsule presentation. Data come from FTIR experiments.

In a similar way, the concentration of the azithromycin in the commercial sample was determined from the slope of the straight line in the simple calibration plot and by extrapolation to $i p=0$ in the addition of standard calibration plot. The results are also presented in Table 1.

It was found that if the FTIR spectroscopy is used, the analysis of azithromycin in capsule can be carried out without applying an extraction method since there are not interferences from other substance in the matrix. Statistical results, with respect to the significance tests, revealed that there are not significant differences between obtained standard deviations for sample concentration in both techniques, with $95 \%$ of probability. Similarly, it is possible to consider that 
there is no matrix effect regarding the patterns, so the analysis can be carried out using both calibration methods. When azithromycin is in suspension, the analysis cannot be carried out because the diluter, which is used to prepare the suspension, contains a mixture of compounds: the sorbitol $\left(\mathrm{C}_{18} \mathrm{H}_{26} \mathrm{O}_{12}\right)$ and the propileneglycol $\left(\mathrm{C}_{3} \mathrm{H}_{8} \mathrm{O}_{2}\right)$. These compounds interfere spectrally with the band from azithromycin, since they present strong absorption in the 2500 to $1250 \mathrm{~cm}^{-1}$ range. A summary of these results is presented in the Table I. Results of the statistical characterization of the proposed methods are also shown in Table I. The recoveries agree with the nominal contents of azithromycin in all cases and the results are compared with those obtained from reported voltammetric and chromatographic methods [18,22]. One of the advantages of the electrochemical method is its direct use in samples with suspension presentation; the comparison of FTIRS and DPV techniques confirmed that FTIRS is more precise, since the standard deviations are lower than those obtained from samples using DPV; however there is not significant differences in the accuracy between these techniques, according to the $\mathrm{F}$ test for a $95 \%$ of confidence.

\section{Conclusions}

The developed electrochemical method for the determination of azithromycin showed to be sensitive, quick and reproducible. This procedure provides good recovery yield and good precision level. Analytical results from electrochemical experiments showed good correlation with results obtained by FTIR spectroscopy. Electrochemical determination of azithromycin has several advantages: the high detection limit, little consuming time, no interference, and low cost of the instrumental setup.

\section{Acknowledgements}

The authors wish to thank to CDCHT-ULA and FONACYT - Venezuela for financial support.

\section{References}

1. G.M. Bright, A.A. Nagel, K.A. Desai, J.N. Dibrino, A.J. Nowakowska, L. Vincent, R.M. Watrous, J. Antibiot. 41 (1998) 1029.

2. H.G. Fouda, R.P. Schneider, Terapeutic Drug Monitoring. 17 (1995) 179.

3. A.E. Girard, D. Girard, A.R. English, T.D. Gootz, C.R. Cimochowski, J.A. Faiella, S.L. Haskell, J.A. Retsema, Antimicrob. Agents Chemother. 31 (1987) 1948.

4. $\quad$ K. Tsuji, J. Chromatogr. 158 (1978) 337.

5. C. Stubbs, J.M. Haigh, I. Kafer, J. Pharm. Sci. 74 (1985) 1126.

6. H. Toreson, B.M. Eriksson, J. Chromatogr. B. 673 (1995) 81.

7. M.L. Chen, W.L. Chiou, J. Chromatogr. 278 (1983) 91.

8. A.E. Girard, D. Girard, J.A. Betsema, J. Antimicrob. Chemother. 25 (suppl.

A) (1990) 61.

9. N. Grgurinovich, A. Matthews, J. Chromatogr. 427 (1988) 93. 
10. J. Retsema, A. Girard, W. Schelkly, M. Manousos, M. Anderson, G. Bright, R. Borovoy, L. Brennan, R. Mason, Antimicrob. Agents Chemother. 31 (1987) 1939.

11. F.M. Demotes-Mainard, G.A. Vicon, C.H. Jarry, H.C. Albin, J. Chromatogr. 490 (1989) 115.

12. G.W. Whitaker, T.D. Lindstrom, J. Liq. Chromatogr. 11 (1988) 3011.

13. P.O. Erah, D.A. Barrentt, P.N. Shaw, J. Chromatogr. B 682 (1996) 73.

14. M. Hedenmo, B.M. Eriksson, J. Chromatogr. 692 (1998 A) 161.

15. R.M. Shepard, G.S. Duthu, R.A. Ferraina, A. Mullins, J. Chromatogr. 565 (1991) 321.

16. R.L. Ortíz, J. Araujo, O.P. Márquez, J. Márquez, in Abstracs of Joint $52^{\text {nd }}$ Meeting of The International Society of Electrochemistry and the $200^{\text {th }}$ Meeting of the Electrochemical Society, San Francisco, USA (2001) 1192.

17. L.G. Nilsson, B. Walldorf, J. Chromatogr. 423 (1987) 189.

18. D. Crotean, F. Valle, M.G. Bergeron, M. Lebel, J. Chromatogr. 419 (1987) 205.

19. E-M.F. Othman, A.L.M. Niveen, Talanta 62 (2004) 531.

20. B. Ntcovle, Anal. Science 20 (2004) 639.

21. S. Sivakesava, J. Irudayaraj, J. Dairy Sci. 85 (2002) 487.

22. M. Gallignani, M.R. Brunetto, Talanta 64 (2004) 1127.

23. R. Gandhi, L.C. Kaul, R. Pachagnula, J. Pharm. Biomed. Anal. 23 (2000) 1073. 